

\title{
Abstract
}

\begin{abstract}
Attention-deficit hyperactivity disorder (ADHD) is one of the most prevalent neurodevelopmental disorders in the pediatric population. The clinical management of ADHD is currently limited by a lack of reliable diagnostic biomarkers and inadequate therapy for a minority of patients that do not respond to standard pharmacotherapy. There is optimism that noninvasive brain stimulation may help to address these limitations. Transcranial magnetic stimulation (TMS) and transcranial direct current stimulation (tDCS) are two methods of noninvasive brain stimulation that modulate cortical excitability and brain network activity. TMS can be used diagnostically to probe cortical neurophysiology, while daily use of repetitive TMS or tDCS can induce long-lasting and potentially therapeutic changes in targeted networks. In this review we highlight research showing the potential diagnostic and therapeutic applications of TMS and tDCS in pediatric ADHD. We also discuss the safety and ethics of using these tools in the pediatric population.
\end{abstract}

Correspondence: rubiobelen@gmail.com or aboes@partners.org..

*Co-Primary Authors.

Belen Rubio, Child and Adolescence Psychiatry Department. Hospital Universitario de Canarias, Carretera de Ofra, s/n, 38320 San Cristóbal de La Laguna, Santa Cruz de Tenerife, Spain. Fax number: +34 922646510

Aaron D. Boes, Berenson-Allen Center for Noninvasive Brain Stimulation, Division of Cognitive Neurology, Department of Neurology, Harvard Medical School and Beth Israel Deaconess Medical Center, 330 Brookline Ave, Boston, MA, 02215

Author contributions

B.R. conceived of the review, performed the literature review, and wrote the manuscript. A.D.B. also wrote the manuscript and reviewed the literature. S.L., A.R., D.J. and A.P.L. all contributed significantly to editing the manuscript and each contributed important ideas to the final product.

Declaration of conflicting interests

A.P.L serves on the scientific advisory boards for Nexstim, Neuronix, Starlab Neuroscience, Neuroelectrics, Neosync, and Novavision, and is listed as inventor in issued patents and patent applications on the real-time integration of transcranial magnetic stimulation (TMS) with electroencephalography (EEG) and magnetic resonance imaging (MRI). 


\author{
Keywords \\ ADHD; pediatric; neuromodulation; TMS; tDCS
}

\title{
Introduction
}

Attention-deficit hyperactivity disorder (ADHD) is one of the most prevalent neurodevelopmental disorders, affecting $2-7.5 \%$ of school-aged children and often persisting into adulthood ${ }^{1-4}$. It is characterized by three core symptoms: inattention, hyperactivity, and impulsivity ${ }^{3}$. Despite intensive study, the pathophysiology of ADHD remains unclear ${ }^{5}$. The clinical management of ADHD is hindered by a lack of widely accepted biomarkers or diagnostic tests. As such, diagnosis is typically made using parentand teacher-reported behavioural rating scales in combination with a physician's clinical impression, without regard to the neural correlates of the individual's symptoms. Pharmacological treatments for ADHD are generally effective and there is strong evidence that treatment improves long-term outcomes in several social and academic domains ${ }^{6}$. Despite the well-established clinical efficacy of available medications ${ }^{7,8}$, a minority of patients do not respond to standard pharmacotherapy, and its use may be limited by side effects and concerns of abuse ${ }^{9-11}$.

Noninvasive brain stimulation may help address some of the aforementioned diagnostic and therapeutic challenges associated with the clinical management of ADHD. Several noninvasive brain stimulation procedures are available to physicians and investigators, and all have in common the capacity to modulate cortical excitability via transcranial electrical stimulation. Of these, the two most common procedures are transcranial magnetic stimulation (TMS) and transcranial direct current stimulation (tDCS), both of which are emerging as realistic clinical tools.

In this review we will briefly highlight leading theories regarding the neural basis of ADHD. We then discuss TMS and tDCS, focusing on their mechanism of neuromodulation, their safety profile in the pediatric population, and their application in ADHD. We also briefly discuss newer neuromodulation techniques and ethical considerations in applying noninvasive brain stimulation to the pediatric population.

\section{Neural Correlates of ADHD}

The exact pathophysiology of ADHD has been difficult to delineate due to complicating factors such as evolving diagnostic criteria, phenotypic heterogeneity, frequent comorbidities, and environmental variables that may exacerbate or mimic symptoms. The three hallmark symptoms of ADHD are each likely to have distinct neural substrates ${ }^{12,13}$, which may obscure attempts to elucidate the pathophysiology from studies that incorporate a variety of clinical presentations. Even well designed neuroimaging studies in ADHD struggle with a variety of potentially confounding variables, such as maturational changes in the brain and motion artifacts from a population that has trouble complying with prolonged MRI studies ${ }^{14}$. Despite these challenges there has been some recent headway in understanding the neural correlates of ADHD. 
One of the most influential theories for the neural basis of ADHD has focused on deficient inhibitory control leading to executive dysfunction ${ }^{15,16}$, which is likely under genetic influence ${ }^{17}$. The neuroanatomical substrate of inhibitory control is believed to involve basal ganglia-thalamo-cortical circuits ${ }^{18,19}$. Specifically, this network links: the prefrontal cortex to the dorsal neostriatum via excitatory glutaminergic cells, the basal ganglia to the dorsomedial thalamus via inhibitory projections, and the thalamus back to the prefrontal cortex via excitatory projections ${ }^{20,21}$. Inhibitory control parallels the maturation of this circuit, and both structural and functional neuroimaging studies reveal differences in this circuit in association with ADHD $22-24$.

A number of other large-scale networks have also been implicated in ADHD. Impulse control deficits have been linked to fronto-striatal circuits, specifically under-activity in the ventrolateral prefrontal cortex, dorsolateral prefrontal cortex and the anterior cingulate ${ }^{25-27}$. Anticipation of reward was shown to correspond with underactivity in the mesolimbic circuit, which includes the ventral striatum and orbitofrontal cortex ${ }^{27,28}$. Spatial working memory deficits are associated with a temporo-parietal circuit ${ }^{29-31}$. As noted, the involvement of these networks is likely to vary by ADHD subtype, which is taken into account with recent studies. ${ }^{12,13}$

To add a layer of complexity to the imaging findings in ADHD, abnormal patterns of brain activity may sometimes represent compensatory changes rather than the primary underlying deficits. For instance, there is a compensatory and likely adaptive increase in posterior parietal activity that accompanies under-activation in fronto-striatal regions during executive tasks $23,27,32-34$.

There are also a large number of ADHD studies showing regional volumetric changes ${ }^{23,24,35-39}$, abnormal trajectory of brain development, ${ }^{37,40}$, abnormal functional connectivity ${ }^{41}$ and abnormal EEG patterns ${ }^{42,43}$ A detailed summary of this work is beyond the scope of this review, but several reviews are available: ${ }^{12,37}$.

Structural and functional differences in the ADHD brain are accompanied by abnormalities of the catecholaminergic neurotransmitters, dopamine and norepinephrine, which are believed to be critical in the pathophysiology of ADHD ${ }^{44,45}$. Low levels of dopamine in prefrontal regions are associated with increased hyperactivity and irritability ${ }^{46}$. Stimulant drugs used in the treatment of ADHD increase dopamine and norepinephrine activity in frontostriatal networks with improvement in symptoms ${ }^{47,48}$.

While acknowledging the complexity of ADHD and the significant limitations in our current understanding of the underlying neural processes, we now turn our attention to noninvasive brain stimulation and its potential utility in pediatric ADHD.

\section{TMS Basics}

Transcranial magnetic stimulation (TMS) is based on the principle of electromagnetic induction: an electric current in the stimulation coil produces a magnetic field, which induces an electric current in nearby conductors, in this case, in the cerebral cortex. The TMS device components include a charging mechanism, the storage capacitor, the thyrister, 
and a discharging coil. The coil design impacts the focality of the resulting stimulation. A circular coil activates a broad area, a figure- 8 coil provides relatively focal stimulation of approximately $5 \mathrm{~mm}^{3}$, and an H-coil targets deeper structures, up to $6 \mathrm{~cm}$ below the stimulation site ${ }^{49,50}$. The induced electrical current triggers action potentials in the brain via current flowing parallel to the surface of the coil. The magnitude of the stimulation is inversely related to the distance from the coil ${ }^{51}$.

\section{Single-Pulse TMS}

The simplest stimulation paradigm for TMS involves applying a single, brief electromagnetic pulse. When a TMS pulse is applied to the motor cortex it can elicit observable motor output, often in the contralateral hand ${ }^{49}$. The motor evoked potential resulting from the TMS pulse can be recorded using electromyography (EMG). When applied to the visual cortex a TMS pulse may induce a visual percept, or a phosphene. The effect of a single TMS pulse on other cortical areas outside the motor and visual cortices can be recorded by scalp EEG or other imaging modalities. The effects of a single TMS pulse are brief and its safety is well established ${ }^{52}$.

\section{Paired-Pulse TMS}

Paired-pulse TMS stimulates the cortex with 2 pulses separated by a variable delay. The main application of this protocol is to measure cortical inhibitory-excitatory balance, which is described in more detail below.

\section{Repetitive TMS}

Repetitive TMS (rTMS) uses a rapid sequence of magnetic pulses to induce longer-lasting modulation of the underlying cortex. Low-frequency rTMS (1 Hz or less) generally has an inhibitory effect on the underlying cortex and high frequency stimulation will typically increase the excitability of the underlying cortex ${ }^{53}$. For example, when applied to the motor cortex, $1 \mathrm{~Hz}$ rTMS will depress the motor evoked potential while $20 \mathrm{~Hz}$ rTMS will increase it ${ }^{54,55}$. Theta-burst stimulation (TBS) is a patterned form of rTMS that requires less stimulation time relative to the duration of effect. For example, a single session with 3 minutes of theta-burst stimulation may modulate the underlying cortex for 30 minutes, and the duration of effect is extended with repeated application. Continuous theta-burst stimulation typically has an inhibitory effect on the underlying cortex, while intermittent theta-burst stimulation is excitatory ${ }^{56}$. Single sessions of TBS in children appear to be safe and well tolerated ${ }^{57}$.

\section{TMS Measures of Cortical Excitability}

There are a few commonly used neurophysiological measures to study cortical excitability, which have relevance as potential diagnostic tests for ADHD. Motor threshold is a proxy of motor cortex excitability ${ }^{58,59}$, and is defined as the minimum intensity of stimulation necessary to elicit a motor evoked potential $(>50 \mu \mathrm{V})$ in a target muscle $50 \%$ of the time ${ }^{53}$.

Paired-pulse TMS protocols are used to assess the intracortical inhibitory-excitatory balance. Varying the interstimulus interval between two TMS pulses leads to reliable alterations in 
the size of the motor evoked potential. The three most commonly used paired-pulse protocols include: short-interval intracortical inhibition (SICI), long-interval intracortical inhibition (LICI), and intracortical facilitation. SICI uses a subthreshold TMS pulse followed by a short interstimulus interval of $1-5 \mathrm{msec}$, then a suprathreshold pulse ${ }^{60}$. The first pulse may activate inhibitory neurons that project to corticospinal neurons, thus lowering the excitability of these corticospinal neurons for the 2nd suprathrshold stimulus ${ }^{60}$. This effect appears to be mediated primarily by $\mathrm{GABA}_{\mathrm{A}},{ }^{61-63}$. LICI uses two suprathreshold pulses at a longer interstimulus interval of $50-100 \mathrm{~ms}$. $\mathrm{GABA}_{\mathrm{B}}$ has a role in mediating the inhibitory effect of the first pulse on the second ${ }^{63}$. Intracortical facilitation uses a subthreshold pulse followed by a suprathreshold pulse, separated by an interstimulus interval of $7-20 \mathrm{~ms}{ }^{60}$. In this case the initial pulse facilitates the motor evoked potential of the second, possibly mediated by NMDA-receptor excitatory neurotransmission ${ }^{60}$.

In addition to using motor output to assess cortical excitability of the motor cortex it is also possible to combine TMS with EEG to probe other cortical regions ${ }^{64}$.

TMS pulses can elicit a characteristic EEG response, termed a TMS-evoked potential. This consists of a set of peaks and volleys in the EEG that occurs along a defined temporal sequence. These tend to be consistent among subjects, and the amplitude can be correlated to other measures of cortical excitability, even at intensities below the motor threshold.

\section{Interhemispheric Connectivity}

Paired pulse stimulation can also be used to study interhemispheric interactions using two TMS coils. The effects of a conditioning stimulus applied to the motor cortex of one hemisphere can affect the motor evoked potential elicited by TMS in the contralateral hemisphere ${ }^{65}$. The motor evoked potential is reduced if the conditioning stimulus in the opposite hemisphere precedes the second stimulus by $7 \mathrm{msec}$ or more ${ }^{65}$. This interhemispheric inhibition appears to occur at the level of motor cortex and it is mediated by transcallosal motor fibers. The ipsilateral cortical silent period is another protocol for assessing interhemispheric interaction. It involves a single TMS pulse to the motor cortex that induces a transient suppression of voluntary tonic muscle activity in the ipsilateral hand muscles, as assessed with EMG ${ }^{65}$. It may be mediated by excitatory transcallosal neurons projecting to contralateral inhibitory interneurons in the homologous region of the motor cortex, thus reflecting the functional integrity of the transcallosal projections between motor cortices ${ }^{65,66}$.

\section{Noninvasive Brain Stimulation in ADHD}

\section{Literature Review Method}

The use of noninvasive brain stimulation in the ADHD pediatric population was searched systematically using MEDLINE. Search terms included [(ADHD) OR (comorbidities) OR (neuroplasticity) OR (child psychiatry) OR (child neurology) OR (adolescents)] AND [(transcranial magnetic stimulation) OR (transcranial direct current stimulation) OR (alternating current stimulation) OR (transcranial random noise stimulation)]. Searches were 
limited to humans under age 18. References of the articles obtained were cross-referenced. The literature review was performed in January of 2015.

\section{TMS as a Diagnostic Tool in ADHD}

Behavioral ratings of hyperactivity in ADHD patients have neurophysiological correlates in the motor cortex, which can be probed with single-pulse and paired-pulse TMS protocols (Table 1). These studies have shown an inverse correlation between SICI and hyperactivity, such that low levels of intracortical inhibition are associated with greater hyperactivity. This suggests that SICI may serve as a biomarker of symptom severity $16,67-69$. Moreover, these abnormalities in SICI improve with administration of methylphenidate ${ }^{67}$. It is not clear if these deficits in cortical inhibition are due to differences at a microscopic scale or from large-scale network properties, or some combination. It is similarly unclear if differences in cortical excitability in ADHD are present throughout the cortex or limited to the motor cortex.

In addition to differences in SICI, transcallosal-mediated inhibition is also deficient in ADHD ${ }^{70-72}$. Both the latency and duration of the ipsilateral silent period is prolonged in children with ADHD ${ }^{70-72}$, with the duration being correlated with hyperactivity and restlessness ${ }^{73}$. The cause of abnormal transcallosal-mediated inhibition in pediatric ADHD is not clear. The ipsilateral silent period normalizes with a single dose of methylphenidate, suggesting that abnormal motor cortex excitability may have a more important role than structural differences in the corpus callosum. This view is also supported by the inverse correlation of ipsilateral silent period duration and magnitude of the SICI ${ }^{54,74}$.

Interestingly, early results of cortical excitability from adults differ from those reported in the pediatric population. Adults with ADHD have less hyperactivity and relatively normal inhibitory motor circuits ${ }^{73}$. Unlike children with ADHD, adults have a shortened ipsilateral silent period with normal latency ${ }^{73}$. These differences between adults and children may relate to developmental differences in the inhibitory intracortical pathways ${ }^{75}$, but additional study is needed. A neurophysiologic correlate of inattentive symptoms in ADHD has not been identified.

TMS-evoked EEG potentials have also been used to assess neurophysiology in ADHD cohorts. The negative deflection of EEG at 100 milliseconds after a TMS pulse, termed the N100, is a proxy of cortical inhibitory processes ${ }^{76-80}$. Recent studies have shown N100 abnormalities in association with ADHD ${ }^{808182}$.

Most of the research to date relevant to TMS-derived neurophysiological measures in ADHD has focused on the motor cortex. TMS-evoked potentials, as described above, will allow future studies to incorporate physiological measures of sites beyond the motor cortex. As methodologies improve and become easier to integrate, future studies may use TMSEEG to probe the neurophysiology of individual networks ${ }^{83,8483}$. The ultimate diagnostic utility of TMS-derived measures may require an integration of multiple parameters to elucidate a neurophysiological profile to which machine learning algorithms could be applied to identify common profiles among patients with ADHD or even subgroups within ADHD cohorts, a technique currently being explored in neuroimaging research ${ }^{13}$. 


\section{TMS in Guiding Pharmacotherapy in ADHD}

To date, the selection of specific medications for ADHD treatment is done empirically, often using trial and error to identify the optimal medication for an individual patient. Current pharmacotherapy is not reliably guided by any disease-specific biomarkers or diagnostic tests, though advances in pharmacognetics may prove useful with further study ${ }^{85}$. It is possible that neurophysiological abnormalities assessed by TMS could also be used for this purpose ${ }^{86}$. Methylphenidate enhances SICI, which has also been reported with other medications that enhance dopaminergic neurotransmission ${ }^{67,87-91}$. Given that SICI is correlated to hyperactivity, and methylphenidate normalizes SICI and improves hyperactivity, it is possible that SICI could be used as an objective and quantitative proxy of the therapeutic effectiveness of methylphenidate. There are a variety of potential uses for this information, such as identifying whether an individual has a greater change in SICI with methylphenidate versus other ADHD medications, or as a way to identify methylphenidate non-responders without the need for a prolonged medication trial. SICI could also be monitored as a way to optimize dosing to adjust for increased weight or increased tolerance over time. SICI could also be tracked when investigating new medications for ADHD. Each of these possibilities would require careful investigation prior to any clinical use. As advances are made in the study of TMS-evoked potentials, it may be possible to assess neurophysiological responses to medications outside of the motor cortex as well ${ }^{83}$.

\section{Therapeutic TMS in ADHD}

An ideal therapy for ADHD should address the underlying nervous system dysfunction, be associated with minimal or no adverse effects, and be financially and practically feasible for use in clinical practice. Pharmacological treatments for ADHD generally meet these goals. However, standard pharmacotherapy is not effective for manyADHD patients, stimulants are sometimes contraindicated, and some patients experience untoward side effects, including cardiovascular, hepatic, growth or suicidal events ${ }^{92,93}$. New interventions are needed to augment or provide alternatives to pharmacotherapy.

Repetitive TMS, when used on a daily basis, can induce long-lasting changes in the excitability of the stimulated site. These functional changes can be leveraged for therapeutic effect, as has been shown for medication-refractory depression in adults ${ }^{94}$. Although there are no current FDA-approved therapeutic uses of TMS in the pediatric population, a multicenter trial is currently underway investigating its role in treating medication-refractory depression ${ }^{95,96}$. With regards to ADHD, there have only been a small number of pilot trials exploring the use of therapeutic TMS in the pediatric population.

In 2012, Weaver et al. performed a pilot trial of 9 adolescents and young adults, age 15-20, using $10 \mathrm{~Hz}$ rTMS to the right dorsolateral prefrontal cortex ${ }^{97}$. Subjects underwent 10 sessions over two weeks and each subject was crossed-over to receive sham. The objective of the study was to assess safety and the conclusion was that this was that rTMS was safe in this cohort, but the study was underpowered to show efficacy. Although the authors reported an improvement in core ADHD symptoms in the treatment group the effect did not differ significantly from the sham condition. 
There have been a few studies of therapeutic rTMS in adults with ADHD, reviewed in Zaman, $2013{ }^{98}$. In 2010, Bloch et al. performed a double blind, randomized, sham controlled crossover pilot study with positive effects in 13 patients ${ }^{99}$. Niederhofer reported improved ADHD symptoms in a case study that involved motor cortex stimulation using 1 Hz rTMS at 1200 pulses per day for 5 days ${ }^{100}$.

To date, however, there are no published large, randomized, sham-controlled trials of therapeutic rTMS in ADHD, though several trials are ongoing (see clinicaltrials.gov for details). Moreover, the optimal target, frequency, and duration are all unknown. It is likely that the target will vary depending on the symptom being treated, as studies have shown distinct neural substrates for distinct ADHD subtypes 12,13.

Safety in Pediatric TMS-The majority of the safety data in TMS is derived from adults. Common side effects of TMS include headache and scalp discomfort, which is experienced by up to $40 \%$ of participants ${ }^{101}$. Rare, but more concerning effects include hearing loss 102,103 or the induction of a seizure with rTMS ${ }^{52}$. The risk of hearing loss can be minimized by using earplugs, and the risk of seizure is estimated at less than 1 in 10,000 when appropriate safety guidelines are adhered to ${ }^{52,104}$.

TMS has been used in over 800 normal children and over 300 neurologically abnormal children, with a good tolerability and safety profile ${ }^{105,106}$. No change in auditory function has been reported in the pediatric population to date ${ }^{105}$. Single- or paired-pulse TMS has not been shown to cause seizures in children, including those with epilepsy or with conditions like cerebral palsy that are associated with increased risk of seizures 101,107-113. One case of rTMS-induced seizure was reported in an adolescent patient being treated for depression ${ }^{114}$, though other risk factors for seizure were also present, including alcohol use the night before the induced seizure ${ }^{95}$. In 2009 , a consensus conference issued recommendations for the safe use TMS in the pediatric population. They concluded that single-pulse and paired-pulse TMS was safe for children two years and older. In the absence of an appreciable volume of data on the potential for adverse effects with rTMS, they recommended that children should not be used as subjects for rTMS without compelling clinical reasons, such as the treatment of particular psychiatric conditions 52 .

\section{tDCS in ADHD}

Transcranial DCS is a noninvasive brain stimulation technique that has received a surge of interest in the last decade. With tDCS, a low-amplitude direct current $(0.5-2 \mathrm{~mA})$ is applied to the scalp via electrodes. Electric current flows from the negatively charged cathode to the positively charged anode, penetrating the skull and modifying neuronal transmembrane potentials in the current path. The effect is to modulate the excitability of a given region, but unlike TMS, tDCS does not deliver suprathreshold currents to induce action potentials ${ }^{115-118}$. The cortex underlying the anode typically becomes more excitable while the cathode site has decreased excitability. The efficacy of tDCS depends on the location, intensity, and duration of the current applied to the brain, which is affected by electrode size and the orientation of the electric field ${ }^{118-120}$. TDCS is a much more diffuse form of 
stimulation than TMS, though smaller electrodes and multi-electrode arrays can be used to improve the spatial resolution.

Enduring changes in brain function after tDCS are documented in the same manner as TMS. When several sessions are applied, the effects can last for several weeks ${ }^{121,122}$. Because tDCS is subthreshold for inducing action potentials the greatest therapeutic benefit may be realized by coupling tDCS sessions with cognitive training. This effect has been leveraged to induce therapeutic effects in disorders such as depression and pain ${ }^{123-126}$.

An ongoing study is investigating the use of tDCS in adult patients with ADHD, which uses anodal tDCS stimulation over the left dorsolateral preftonal cortex at $1 \mathrm{~mA}^{127}$. The aim of this parallel, randomized, double-blind, sham-controlled trial is to study the modulation of inhibitory control in this population. While the results of tDCS in ADHD are not yet available there is a burgeoning literature suggesting that tDCS may be used to improve cognitive performance. These studies have shown that tDCS can improve behavioural inhibition, memory, and attention in healthy subjects ${ }^{128,129}$, and these findings extend to clinical populations ${ }^{127,130}$. There is reason to be optimistic that similar stimulation paradigms may have a beneficial effect for ADHD patients, though it will be critical that future studies be sufficiently powered and include a sham-controlled experimental design.

If tDCS is effective for certain symptoms of ADHD it may offer many advantages over rTMS as a therapy. For example, the stimulators are relatively inexpensive compared to TMS equipment and application requires less cooperation from the patient relative to rTMS, which may be important for hyperactive children. Moreover, the safety profile of tDCS is excellent and the main recognized side effects include an itching sensation and skin redness under the electrode ${ }^{106,119}$.

\section{Newer Noninvasive Brain Stimulation Tools}

Two new promising neuromodulation techniques include transcranial alternating current stimulation (tACS) and transcranial random noise stimulation (tRNS). TACS is similar to tDCS but the current alternates at a specific frequency. This can alter the oscillatory frequencies in regions being stimulated. A recent study of 12 children with ADHD showed that $0.75 \mathrm{~Hz}$ tACS during slow wave sleep improved declarative memory consolidation to normal levels ${ }^{130}$. Given prior research highlighting abnormal oscillatory activity in the ADHD brain, such as an elevated theta-to-beta ratio in fronto-central leads ${ }^{131}$, it is possible that normalizing these patterns via tACS may be therapeutic. TRNS is similar to tACS except instead of a defined frequency the alternating current is random, resembling noise ${ }^{132}$. It may act by introducing noise into a system to increase the signal- to-noise ratio ${ }^{133}$. Although tRNS has not been used in ADHD to date, it has improved cognitive parameters for healthy controls ${ }^{134}$.

\section{Ethics of Noninvasive Brain Stimulation in Pediatric ADHD}

There are major questions raised by the prospect of inducing functional changes in a child's brain through exogenous stimulation. This includes, but is not limited to: possible long-term effects, access to this technology and cognitive domain performance trade-offs. In fact, there is evidence that while therapeutic brain stimulation can result in benefits in certain domains, 
others can become impaired ${ }^{135,136}$. Given the availability of transcranial electrical stimulation devices and direct-to-consumer marketing, one major ethical concern is the proliferation of non-medical use. If a company markets tDCS equipment using non-medical terms (e.g. to enhance focus) it may bypass the regulatory processes in place for medical devices, potentially making transcranial stimulation available to consumers prior to carefully monitored clinical trials that are needed to rigorously establish the optimal parameters of use, efficacy and side effect profile. In addition, there is no guarantee that safety data derived from adult trials will carry-over to the pediatric population. As such, we must proceed forward with great caution and foresight. For excellent discussions of the ethics of pediatric brain stimulation see 137,138 .

\section{Conclusion}

This review highlights studies that build early support for the cautious extension of research into the diagnostic and therapeutic use of noninvasive brain stimulation in pediatric ADHD. While the current evidence is admittedly limited, there is reason to be optimistic. With respect to therapy, the developing brain is believed to be more plastic than its adult counterpart, and thus is likely to be more easily influenced by neuromodulation. Supportive of this concept, one of the predictors of better response to rTMS therapy in adult depression is younger age ${ }^{139,140}$, and early results of therapeutic neuromodulation in the pediatric population are encouraging. However, increased plasticity in the pediatric brain may also correspond to increased vulnerability to unintended changes induced by neuromodulation. Researchers must proceed cautiously with a high level of vigilance for side effects. Exactly how noninvasive brain stimulation can be optimally integrated with current clinical management of ADHD will require years of intensive study, but the pervasiveness of ADHD and the need for improved management should make this endeavour a high priority.

\section{Acknowledgments}

Funding

A.D.B. was supported by NIH/NINDS grant 5R25NS065743-05.

\section{REFERENCES}

1. Faraone SV, Biederman J, Mick E. The age-dependent decline of attention deficit hyperactivity disorder: a meta-analysis of follow-up studies. Psychol Med. 2006; 36(2):159-165. doi:10.1017/ S003329170500471X. [PubMed: 16420712]

2. Barkley RA, Fischer M, Smallish L, Fletcher K. The persistence of attention-deficit/hyperactivity disorder into young adulthood as a function of reporting source and definition of disorder. $\mathrm{J}$ Abnorm Psychol. 2002; 111(2):279-289. http://www.ncbi.nlm.nih.gov/pubmed/12003449. [PubMed: 12003449]

3. American Psychiatric Association. Diagnostic and Statistical Manual of Mental Disorders. 5th Ed. 2013. http://ajp.psychiatryonline.org/article.aspx?articleID $=158714$

4. Hinshaw SP, Owens EB, Zalecki C, et al. Prospective follow-up of girls with attention-deficit/ hyperactivity disorder into early adulthood: continuing impairment includes elevated risk for suicide attempts and self-injury. J Consult Clin Psychol. 2012; 80(6):1041-1051. doi:10.1037/a0029451. [PubMed: 22889337]

5. Matthews M, Nigg JT, Fair DA. Attention deficit hyperactivity disorder. Curr Top Behav Neurosci. 2014; 16:235-266. doi:10.1007/7854_2013_249. [PubMed: 24214656] 
6. Banaschewski T, Soutullo C, Lecendreux M, et al. Health-related quality of life and functional outcomes from a randomized, controlled study of lisdexamfetamine dimesylate in children and adolescents with attention deficit hyperactivity disorder. CNS Drugs. 2013; 27(10):829-840. doi: 10.1007/s40263-013-0095-5. [PubMed: 23893527]

7. Goldman LS, Genel M, Bezman RJ, Slanetz PJ. Diagnosis and treatment of attention-deficit/ hyperactivity disorder in children and adolescents. Council on Scientific Affairs, American Medical Association. JAMA. 1998; 279(14):1100-1107. http://www.ncbi.nlm.nih.gov/pubmed/9546570. [PubMed: 9546570]

8. Biederman J, Faraone SV. Attention-deficit hyperactivity disorder. Lancet. 366(9481):237-248. doi: 10.1016/S0140-6736(05)66915-2. [PubMed: 16023516]

9. Arnold LE, Abikoff HB, Cantwell DP, et al. National Institute of Mental Health Collaborative Multimodal Treatment Study of Children with ADHD (the MTA). Design challenges and choices. Arch Gen Psychiatry. 1997; 54(9):865-870. http://www.ncbi.nlm.nih.gov/pubmed/9294378. [PubMed: 9294378]

10. Faraone SV, Biederman J, Spencer TJ, Aleardi M. Comparing the efficacy of medications for ADHD using meta-analysis. MedGenMed. 2006; 8(4):4. http://www.pubmedcentral.nih.gov/ articlerender.fcgi?artid=1868385-tool=pmcentrez-rendertype=abstract. [PubMed: 17415287]

11. Clemow DB, Walker DJ. The potential for misuse and abuse of medications in ADHD: a review. Postgrad Med. 2014; 126(5):64-81. doi:10.3810/pgm.2014.09.2801. [PubMed: 25295651]

12. Rubia K, Alegria AA, Brinson H. Brain abnormalities in attention-deficit hyperactivity disorder: a review. Rev Neurol. 2014; 58(S01):S3-S18. [PubMed: 25252664]

13. Fair DA, Nigg JT, Iyer $S$, et al. Distinct neural signatures detected for ADHD subtypes after controlling for micro-movements in resting state functional connectivity MRI data. Front Syst Neurosci. 2013; 6:80. doi:10.3389/fnsys.2012.00080. [PubMed: 23382713]

14. Di Martino A, Fair DA, Kelly C, et al. Unraveling the Miswired Connectome: A Developmental Perspective. Neuron. 2014; 83(6):1335-1353. doi:10.1016/j.neuron.2014.08.050. [PubMed: 25233316]

15. Sonuga-Barke EJS. Causal models of attention-deficit/hyperactivity disorder: from common simple deficits to multiple developmental pathways. Biol Psychiatry. 2005; 57(11):1231-1238. doi: 10.1016/j.biopsych.2004.09.008. [PubMed: 15949993]

16. Gilbert DL, Isaacs KM, Augusta M, Macneil LK, Mostofsky SH. Motor cortex inhibition: a marker of ADHD behavior and motor development in children. Neurology. 2011; 76(7):615-621. doi: 10.1212/WNL.0b013e31820c2ebd. [PubMed: 21321335]

17. Goos LM, Crosbie J, Payne S, Schachar R. Validation and extension of the endophenotype model in ADHD patterns of inheritance in a family study of inhibitory control. Am J Psychiatry. 2009; 166(6):711-717. doi:10.1176/appi.ajp.2009.08040621. [PubMed: 19448185]

18. Alexander GE, Crutcher MD, DeLong MR. Basal ganglia-thalamocortical circuits: parallel substrates for motor, oculomotor, "prefrontal" and "limbic" functions. Prog Brain Res. 1990; 85:119-146. doi:10.1016/S0079-6123(08)62678-3. [PubMed: 2094891]

19. Christakou A, Robbins TW, Everitt BJ. Prefrontal cortical-ventral striatal interactions involved in affective modulation of attentional performance: implications for corticostriatal circuit function. $\mathrm{J}$ Neurosci. 2004; 24(4):773-780. doi:10.1523/JNEUROSCI.0949-03.2004. [PubMed: 14749421]

20. Aron AR, Robbins TW, Poldrack RA. Inhibition and the right inferior frontal cortex. Trends Cogn Sci. 2004; 8(4):170-177. doi:10.1016/j.tics.2004.02.010. [PubMed: 15050513]

21. Aron AR, Monsell S, Sahakian BJ, Robbins TW. A componential analysis of task-switching deficits associated with lesions of left and right frontal cortex. Brain. 2004; 127(Pt 7):1561-1573. doi:10.1093/brain/awh169. [PubMed: 15090477]

22. Castellanos FX, Lee PP, Sharp W, et al. Developmental trajectories of brain volume abnormalities in children and adolescents with attention-deficit/hyperactivity disorder. JAMA. 2002; 288(14): 1740-1748. http://www.ncbi.nlm.nih.gov/pubmed/12365958. [PubMed: 12365958]

23. Rubia K, Overmeyer S, Taylor E, et al. Hypofrontality in attention deficit hyperactivity disorder during higher-order motor control: a study with functional MRI. Am J Psychiatry. 1999; 156(6): 891-896. http://www.ncbi.nlm.nih.gov/pubmed/10360128. [PubMed: 10360128] 
24. Batty MJ, Liddle EB, Pitiot A, et al. Cortical gray matter in attention-deficit/hyperactivity disorder: a structural magnetic resonance imaging study. J Am Acad Child Adolesc Psychiatry. 2010; 49(3): 229-238. http://www.pubmedcentral.nih.gov/articlerender.fcgi?artid=2829134-tool=pmcentrezrendertype $=$ abstract. [PubMed: 20410712]

25. Konrad K, Neufang S, Hanisch C, Fink GR, Herpertz-Dahlmann B. Dysfunctional attentional networks in children with attention deficit/hyperactivity disorder: evidence from an event-related functional magnetic resonance imaging study. Biol Psychiatry. 2006; 59(7):643-651. doi:10.1016/ j.biopsych.2005.08.013. [PubMed: 16197925]

26. Dickstein SG, Bannon K, Castellanos FX, Milham MP. The neural correlates of attention deficit hyperactivity disorder: an ALE meta-analysis. J Child Psychol Psychiatry. 2006; 47(10):10511062. doi:10.1111/j.1469-7610.2006.01671.x. [PubMed: 17073984]

27. Vaidya CJ, Stollstorff M. Cognitive neuroscience of Attention Deficit Hyperactivity Disorder: current status and working hypotheses. Dev Disabil Res Rev. 2008; 14(4):261-267. doi:10.1002/ ddrr.40. [PubMed: 19072750]

28. Ruffini C, Locatelli M, Lucca A, Benedetti F, Insacco C, Smeraldi E. Augmentation effect of repetitive transcranial magnetic stimulation over the orbitofrontal cortex in drug-resistant obsessive-compulsive disorder patients: a controlled investigation. Prim Care Companion J Clin Psychiatry. 2009; 11(5):226-230. doi:10.4088/PCC.08m00663. [PubMed: 19956460]

29. Vance A, Silk TJ, Casey M, et al. Right parietal dysfunction in children with attention deficit hyperactivity disorder, combined type: a functional MRI study. Mol Psychiatry. 2007; 12(9):826832. 793. doi:10.1038/sj.mp.4001999. [PubMed: 17471290]

30. Silk T, Vance A, Rinehart N, et al. Fronto-parietal activation in attention-deficit hyperactivity disorder, combined type: functional magnetic resonance imaging study. Br J Psychiatry. 2005; 187:282-283. doi:10.1192/bjp.187.3.282. [PubMed: 16135867]

31. Shafritz KM, Marchione KE, Gore JC, Shaywitz SE, Shaywitz BA. The effects of methylphenidate on neural systems of attention in attention deficit hyperactivity disorder. Am J Psychiatry. 2004; 161(11):1990-1997. doi:10.1176/appi.ajp.161.11.1990. [PubMed: 15514398]

32. Durston S, Tottenham NT, Thomas KM, et al. Differential patterns of striatal activation in young children with and without ADHD. Biol Psychiatry. 2003; 53(10):871-878. http:// www.ncbi.nlm.nih.gov/pubmed/12742674. [PubMed: 12742674]

33. Fassbender C, Schweitzer JB. Is there evidence for neural compensation in attention deficit hyperactivity disorder? A review of the functional neuroimaging literature. Clin Psychol Rev. 2006; 26(4):445-465. doi:10.1016/j.cpr.2006.01.003. [PubMed: 16500007]

34. Schweitzer JB, Faber TL, Grafton ST, Tune LE, Hoffman JM, Kilts CD. Alterations in the functional anatomy of working memory in adult attention deficit hyperactivity disorder. Am J Psychiatry. 2000; 157(2):278-280. http://www.ncbi.nlm.nih.gov/pubmed/10671402. [PubMed: 10671402]

35. Castellanos FX, Giedd JN, Marsh WL, et al. Quantitative brain magnetic resonance imaging in attention-deficit hyperactivity disorder. Arch Gen Psychiatry. 1996; 53(7):607-616. http:// www.ncbi.nlm.nih.gov/pubmed/8660127. [PubMed: 8660127]

36. Sowell ER, Thompson PM, Welcome SE, Henkenius AL, Toga AW, Peterson BS. Cortical abnormalities in children and adolescents with attention-deficit hyperactivity disorder. Lancet. 2003; 362(9397):1699-1707. doi:10.1016/S0140-6736(03)14842-8. [PubMed: 14643117]

37. Shaw P, Rabin C. New insights into attention-deficit/hyperactivity disorder using structural neuroimaging. Curr Psychiatry Rep. 2009; 11(5):393-398. [PubMed: 19785981]

38. Shaw P, Gornick M, Lerch J, et al. Polymorphisms of the dopamine D4 receptor, clinical outcome, and cortical structure in attention-deficit/hyperactivity disorder. Arch Gen Psychiatry. 2007; 64(8): 921-931. doi:10.1001/archpsyc.64.8.921. [PubMed: 17679637]

39. Valera EM, Faraone SV, Murray KE, Seidman LJ. Meta-analysis of structural imaging findings in attention-deficit/hyperactivity disorder. Biol Psychiatry. 2007; 61(12):1361-1369. doi:10.1016/ j.biopsych.2006.06.011. [PubMed: 16950217]

40. Rapoport JL, Gogtay N. Brain neuroplasticity in healthy, hyperactive and psychotic children: insights from neuroimaging. Neuropsychopharmacology. 2008; 33(1):181-197. doi:10.1038/ sj.npp.1301553. [PubMed: 17851542] 
41. Li F, He N, Li Y, et al. Intrinsic brain abnormalities in attention deficit hyperactivity disorder: a resting-state functional MR imaging study. Radiology. 2014; 272(2):514-523. doi:10.1148/radiol. 14131622. [PubMed: 24785156]

42. Zang Y-F, He Y, Zhu C-Z, et al. Altered baseline brain activity in children with ADHD revealed by resting-state functional MRI. Brain Dev. 2007; 29(2):83-91. doi:10.1016/j.braindev.2006.07.002. [PubMed: 16919409]

43. Wang L, Zhu C, He Y, et al. Altered small-world brain functional networks in children with attention-deficit/hyperactivity disorder. Hum Brain Mapp. 2009; 30(2):638-649. doi:10.1002/hbm. 20530. [PubMed: 18219621]

44. Solanto MV. Dopamine dysfunction in AD/HD: integrating clinical and basic neuroscience research. Behav Brain Res. 2002; 130(1-2):65-71. http://www.ncbi.nlm.nih.gov/pubmed/ 11864719. [PubMed: 11864719]

45. Nieoullon A, Coquerel A. Dopamine: a key regulator to adapt action, emotion, motivation and cognition. Curr Opin Neurol. 2003; 16(Suppl 2):S3-S9. http://www.ncbi.nlm.nih.gov/pubmed/ 15129844. [PubMed: 15129844]

46. Comings DE. Tourette syndrome: a hereditary neuropsychiatric spectrum disorder. Ann Clin Psychiatry. 1994; 6(4):235-247. http://www.ncbi.nlm.nih.gov/pubmed/7647833. [PubMed: 7647833]

47. Volkow ND, Ding YS, Fowler JS, et al. Is methylphenidate like cocaine? Studies on their pharmacokinetics and distribution in the human brain. Arch Gen Psychiatry. 1995; 52(6):456-463. http://www.ncbi.nlm.nih.gov/pubmed/7771915. [PubMed: 7771915]

48. Arnsten AF, Dudley AG. Methylphenidate improves prefrontal cortical cognitive function through alpha2 adrenoceptor and dopamine D1 receptor actions: Relevance to therapeutic effects in Attention Deficit Hyperactivity Disorder. Behav Brain Funct. 2005; 1(1):2. doi: 10.1186/1744-9081-1-2. [PubMed: 15916700]

49. Kobayashi M, Pascual-Leone A. Transcranial magnetic stimulation in neurology. Lancet Neurol. 2003; 2(3):145-156. http://www.ncbi.nlm.nih.gov/pubmed/12849236. [PubMed: 12849236]

50. Roth Y, Amir A, Levkovitz Y, Zangen A. Three-dimensional distribution of the electric field induced in the brain by transcranial magnetic stimulation using figure- 8 and deep H-coils. J Clin Neurophysiol. 2007; 24(1):31-38. doi:10.1097/WNP.0b013e31802fa393. [PubMed: 17277575]

51. Maeda F, Pascual-Leone A. Transcranial magnetic stimulation: studying motor neurophysiology of psychiatric disorders. Psychopharmacology (Berl). 2003; 168(4):359-376. doi:10.1007/ s00213-002-1216-x. [PubMed: 12830365]

52. Rossi S, Hallett M, Rossini PM, Pascual-Leone A. Safety, ethical considerations, and application guidelines for the use of transcranial magnetic stimulation in clinical practice and research. Clin Neurophysiol. 2009; 120(12):2008-2039. doi:10.1016/j.clinph.2009.08.016. [PubMed: 19833552]

53. Theodore WH. Handbook of Transcranial Magnetic Stimulation. Epilepsy Behav. 2002; 3(4):404. Edited by A. Pascual-Leone, N.J. Davey, J. Rothwell, E.M. Wasseran, B.K. Puri, Arnold, London, 2001. pound 110 sterling, ISBN 0340720093. http://www.ncbi.nlm.nih.gov/pubmed/12609342.

54. Chen R, Tam A, Bütefisch C, et al. Intracortical inhibition and facilitation in different representations of the human motor cortex. J Neurophysiol. 1998; 80(6):2870-2881. http:// www.ncbi.nlm.nih.gov/pubmed/9862891. [PubMed: 9862891]

55. Guse B, Falkai P, Wobrock T. Cognitive effects of high-frequency repetitive transcranial magnetic stimulation: a systematic review. J Neural Transm. 2010; 117(1):105-122. doi:10.1007/ s00702-009-0333-7. [PubMed: 19859782]

56. Huang Y-Z, Edwards MJ, Rounis E, Bhatia KP, Rothwell JC. Theta burst stimulation of the human motor cortex. Neuron. 2005; 45(2):201-206. doi:10.1016/j.neuron.2004.12.033. [PubMed: 15664172]

57. Wu SW, Shahana N, Huddleston DA, Lewis AN, Gilbert DL. Safety and tolerability of theta-burst transcranial magnetic stimulation in children. Dev Med Child Neurol. 2012; 54(7):636-639. doi: 10.1111/j.1469-8749.2012.04300.x. [PubMed: 22515662]

58. Amassian VE, Stewart M, Quirk GJ, Rosenthal JL. Physiological basis of motor effects of a transient stimulus to cerebral cortex. Neurosurgery. 1987; 20(1):74-93. http:// www.ncbi.nlm.nih.gov/pubmed/3543727. [PubMed: 3543727] 
59. Shimazu H, Maier MA, Cerri G, Kirkwood PA, Lemon RN. Macaque ventral premotor cortex exerts powerful facilitation of motor cortex outputs to upper limb motoneurons. J Neurosci. 2004; 24(5):1200-1211. doi:10.1523/JNEUROSCI.4731-03.2004. [PubMed: 14762138]

60. Kujirai T, Caramia MD, Rothwell JC, et al. Corticocortical inhibition in human motor cortex. J Physiol. 1993; 471:501-519. http://www.pubmedcentral.nih.gov/articlerender.fcgi?artid=1143973tool=pmcentrez-rendertype $=$ abstract. [PubMed: 8120818]

61. Di Lazzaro V, Oliviero A, Saturno E, et al. Effects of lorazepam on short latency afferent inhibition and short latency intracortical inhibition in humans. J Physiol. 2005; 564(Pt 2):661-668. doi: 10.1113/jphysiol.2004.061747. [PubMed: 15718269]

62. Ziemann U, Lönnecker S, Steinhoff BJ, Paulus W. The effect of lorazepam on the motor cortical excitability in man. Exp brain Res. 1996; 109(1):127-135. http://www.ncbi.nlm.nih.gov/pubmed/ 8740215. [PubMed: 8740215]

63. McDonnell MN, Orekhov Y, Ziemann U. The role of GABA(B) receptors in intracortical inhibition in the human motor cortex. Exp brain Res. 2006; 173(1):86-93. doi:10.1007/s00221-006-0365-2. [PubMed: 16489434]

64. Miniussi C, Thut G. Combining TMS and EEG Offers New Prospects in Cognitive Neuroscience. Brain Topogr. 2009; 22(4):249-256. doi:10.1007/s10548-009-0083-8. [PubMed: 19241152]

65. Ferbert A, Priori A, Rothwell JC, Day BL, Colebatch JG, Marsden CD. Interhemispheric inhibition of the human motor cortex. J Physiol. 1992; 453:525-546. http://www.pubmedcentral.nih.gov/ articlerender.fcgi?artid=1175572-tool=pmcentrez-rendertype=abstract. [PubMed: 1464843]

66. Meyer BU, Röricht S, Gräfin von Einsiedel H, Kruggel F, Weindl A. Inhibitory and excitatory interhemispheric transfers between motor cortical areas in normal humans and patients with abnormalities of the corpus callosum. Brain. 1995; 118(Pt 2):429-440. http:// www.ncbi.nlm.nih.gov/pubmed/7735884. [PubMed: 7735884]

67. Buchmann J, Gierow W, Weber S, et al. Restoration of disturbed intracortical motor inhibition and facilitation in attention deficit hyperactivity disorder children by methylphenidate. Biol Psychiatry. 2007; 62(9):963-969. doi:10.1016/j.biopsych.2007.05.010. [PubMed: 17719015]

68. Gilbert DL, Bansal AS, Sethuraman G, et al. Association of cortical disinhibition with tic, ADHD, and OCD severity in Tourette syndrome. Mov Disord. 2004; 19(4):416-425. doi:10.1002/mds. 20044. [PubMed: 15077239]

69. Gilbert DL, Sallee FR, Zhang J, Lipps TD, Wassermann EM. Transcranial magnetic stimulationevoked cortical inhibition: a consistent marker of attention-deficit/hyperactivity disorder scores in tourette syndrome. Biol Psychiatry. 2005; 57(12):1597-1600. doi:10.1016/j.biopsych.2005.02.022. [PubMed: 15953499]

70. Buchmann J, Wolters A, Haessler F, Bohne S, Nordbeck R, Kunesch E. Disturbed transcallosally mediated motor inhibition in children with attention deficit hyperactivity disorder (ADHD). Clin Neurophysiol. 2003; 114(11):2036-2042. http://www.ncbi.nlm.nih.gov/pubmed/14580601. [PubMed: 14580601]

71. Buchmann J, Gierow W, Weber S, et al. Modulation of transcallosally mediated motor inhibition in children with attention deficit hyperactivity disorder (ADHD) by medication with methylphenidate (MPH). Neurosci Lett. 2006; 405(1-2):14-18. doi:10.1016/j.neulet.2006.06.026. [PubMed: 16815631]

72. Garvey MA, Barker CA, Bartko JJ, et al. The ipsilateral silent period in boys with attention-deficit/ hyperactivity disorder. Clin Neurophysiol. 2005; 116(8):1889-1896. doi:10.1016/j.clinph. 2005.03.018. [PubMed: 15979402]

73. Hoeppner J, Wandschneider R, Neumeyer M, et al. Impaired transcallosally mediated motor inhibition in adults with attention-deficit/hyperactivity disorder is modulated by methylphenidate. J Neural Transm. 2008; 115(5):777-785. doi:10.1007/s00702-007-0008-1. [PubMed: 18196200]

74. Trompetto C, Buccolieri A, Marchese R, Marinelli L, Michelozzi G, Abbruzzese G. Impairment of transcallosal inhibition in patients with corticobasal degeneration. Clin Neurophysiol. 2003; 114(11):2181-2187. http://www.ncbi.nlm.nih.gov/pubmed/14580617. [PubMed: 14580617]

75. Walther M, Berweck S, Schessl J, et al. Maturation of inhibitory and excitatory motor cortex pathways in children. Brain Dev. 2009; 31(7):562-567. doi:10.1016/j.braindev.2009.02.007. [PubMed: 19329268] 
76. Nikulin VV, Kicić D, Kähkönen S, Ilmoniemi RJ. Modulation of electroencephalographic responses to transcranial magnetic stimulation: evidence for changes in cortical excitability related to movement. Eur J Neurosci. 2003; 18(5):1206-1212. http://www.ncbi.nlm.nih.gov/pubmed/ 12956719. [PubMed: 12956719]

77. Bender S, Basseler K, Sebastian I, et al. Electroencephalographic response to transcranial magnetic stimulation in children: Evidence for giant inhibitory potentials. Ann Neurol. 2005; 58(1):58-67. doi:10.1002/ana.20521. [PubMed: 15984026]

78. Bikmullina R, Kicić D, Carlson S, Nikulin VV. Electrophysiological correlates of short-latency afferent inhibition: a combined EEG and TMS study. Exp brain Res. 2009; 194(4):517-526. doi: 10.1007/s00221-009-1723-7. [PubMed: 19241068]

79. Bonnard M, Spieser L, Meziane HB, de Graaf JB, Pailhous J. Prior intention can locally tune inhibitory processes in the primary motor cortex: direct evidence from combined TMS-EEG. Eur J Neurosci. 2009; 30(5):913-923. doi:10.1111/j.1460-9568.2009.06864.x. [PubMed: 19712104]

80. Bruckmann S, Hauk D, Roessner V, et al. Cortical inhibition in attention deficit hyperactivity disorder: new insights from the electroencephalographic response to transcranial magnetic stimulation. Brain. 2012; 135(Pt 7):2215-2230. doi:10.1093/brain/aws071. [PubMed: 22492560]

81. Helfrich C, Pierau SS, Freitag CM, Roeper J, Ziemann U, Bender S. Monitoring cortical excitability during repetitive transcranial magnetic stimulation in children with ADHD: a singleblind, sham-controlled TMS-EEG study. PLoS One. 2012; 7(11):e50073. doi:10.1371/ journal.pone.0050073. [PubMed: 23185537]

82. D’Agati E, Hoegl T, Dippel G, et al. Motor cortical inhibition in ADHD: modulation of the transcranial magnetic stimulation-evoked N100 in a response control task. J Neural Transm. 2014; 121(3):315-325. doi:10.1007/s00702-013-1097-7. [PubMed: 24126573]

83. Bortoletto M, Veniero D, Thut G, Miniussi C. The contribution of TMS-EEG coregistration in the exploration of the human cortical connectome. Neurosci Biobehav Rev. 2014; 49C:114-124. doi: 10.1016/j.neubiorev.2014.12.014. [PubMed: 25541459]

84. Rogasch NC, Fitzgerald PB. Assessing cortical network properties using TMS-EEG. Hum Brain Mapp. 2013; 34(7):1652-1669. doi:10.1002/hbm.22016. [PubMed: 22378543]

85. Bruxel EM, Akutagava-Martins GC, Salatino-Oliveira A, et al. ADHD pharmacogenetics across the life cycle: New findings and perspectives. Am J Med Genet B Neuropsychiatr Genet. 2014; 165B(4):263-282. doi:10.1002/ajmg.b.32240. [PubMed: 24804845]

86. Kapogiannis D, Wassermann EM. Transcranial magnetic stimulation in Clinical Pharmacology. Cent Nerv Syst Agents Med Chem. 2008; 8(4):234-240. http://www.pubmedcentral.nih.gov/ articlerender.fcgi?artid=2613312-tool=pmcentrez-rendertype=abstract. [PubMed: 19122782 ]

87. Korchounov A, Ilić TV, Ziemann U. TMS-assisted neurophysiological profiling of the dopamine receptor agonist cabergoline in human motor cortex. J Neural Transm. 2007; 114(2):223-229. doi: 10.1007/s00702-006-0523-5. [PubMed: 16868794]

88. Schneider MKF, Retz W, Gougleris G, Verhoeven WMA, Tulen JHM, Rösler M. Effects of longacting methylphenidate in adults with attention deficit hyperactivity disorder: a study with pairedpulse transcranial magnetic stimulation. Neuropsychobiology. 2011; 64(4):195-201. doi: 10.1159/000326693. [PubMed: 21912187]

89. Ziemann U, Bruns D, Paulus W. Enhancement of human motor cortex inhibition by the dopamine receptor agonist pergolide: evidence from transcranial magnetic stimulation. Neurosci Lett. 1996; 208(3):187-190. http://www.ncbi.nlm.nih.gov/pubmed/8733301. [PubMed: 8733301]

90. Ziemann U, Tergau F, Bruns D, Baudewig J, Paulus W. Changes in human motor cortex excitability induced by dopaminergic and anti-dopaminergic drugs. Electroencephalogr Clin Neurophysiol. 1997; 105(6):430-437. http://www.ncbi.nlm.nih.gov/pubmed/9448644. [PubMed: 9448644]

91. Kratz O, Diruf MS, Studer P, et al. Effects of methylphenidate on motor system excitability in a response inhibition task. Behav Brain Funct. 2009; 5:12. doi:10.1186/1744-9081-5-12. [PubMed: 19250519]

92. Wilens TE, McBurnett K, Bukstein O, et al. Multisite controlled study of OROS methylphenidate in the treatment of adolescents with attention-deficit/hyperactivity disorder. Arch Pediatr Adolesc Med. 2006; 160(1):82-90. doi:10.1001/archpedi.160.1.82. [PubMed: 16389216] 
93. May DE, Kratochvil CJ. Attention-deficit hyperactivity disorder: recent advances in paediatric pharmacotherapy. Drugs. 2010; 70(1):15-40. doi:10.2165/11530540-000000000-00000. [PubMed: 20030423]

94. Gaynes BN, Lloyd SW, Lux L, et al. Repetitive transcranial magnetic stimulation for treatmentresistant depression: a systematic review and meta-analysis. J Clin Psychiatry. 2014; 75(5):477489. quiz 489. doi:10.4088/JCP.13r08815. [PubMed: 24922485]

95. Wall C, Croarkin P, Bandel L, Schaefer K. Response to repetitive transcranial magnetic stimulation induced seizures in an adolescent patient with major depression: a case report. Brain Stimul. 7(2): 337-338. doi:10.1016/j.brs.2013.12.001. [PubMed: 24629832]

96. Rajapakse T, Kirton A. NON-INVASIVE BRAIN STIMULATION IN CHILDREN: APPLICATIONS AND FUTURE DIRECTIONS. Trans1 Neurosci. 2013; 4(2) doi:10.2478/ s13380-013-0116-3.

97. Weaver L, Rostain AL, Mace W, Akhtar U, Moss E, O'Reardon JP. Transcranial magnetic stimulation (TMS) in the treatment of attention-deficit/hyperactivity disorder in adolescents and young adults: a pilot study. J ECT. 2012; 28(2):98-103. doi:10.1097/YCT.0b013e31824532c8. [PubMed: 22551775]

98. Zaman R. Adult-ADHD and potential role of transcranial magnetic stimulation (TMS and rTMS) investigation and treatment. Psychiatr Danub. 2013; 25(Suppl 2):S366-S367. http:// www.ncbi.nlm.nih.gov/pubmed/23995211. [PubMed: 23995211]

99. Bloch Y, Harel EV, Aviram S, Govezensky J, Ratzoni G, Levkovitz Y. Positive effects of repetitive transcranial magnetic stimulation on attention in ADHD Subjects: a randomized controlled pilot study. World J Biol Psychiatry. 2010; 11(5):755-758. doi:10.3109/15622975.2010.484466. [PubMed: 20521875]

100. Niederhofer H. Effectiveness of the repetitive Transcranical Magnetic Stimulation (rTMS) of $1 \mathrm{~Hz}$ for Attention-Deficit Hyperactivity Disorder (ADHD). Psychiatr Danub. 2008; 20(1):91-92. [PubMed: 18376338]

101. Loo CK, McFarquhar TF, Mitchell PB. A review of the safety of repetitive transcranial magnetic stimulation as a clinical treatment for depression. Int J Neuropsychopharmacol. 2008; 11(1):131147. doi:10.1017/S1461145707007717. [PubMed: 17880752]

102. Loo C, Sachdev P, Elsayed H, et al. Effects of a 2- to 4-week course of repetitive transcranial magnetic stimulation (rTMS) on neuropsychologic functioning, electroencephalogram, and auditory threshold in depressed patients. Biol Psychiatry. 2001; 49(7):615-623. doi:10.1016/ S0006-3223(00)00996-3. [PubMed: 11297719]

103. Pascual-Leone A, Houser CM, Reese K, et al. Safety of rapid-rate transcranial magnetic stimulation in normal volunteers. Electroencephalogr Clin Neurophysiol. 1993; 89(2):120-130. [PubMed: 7683602]

104. Janicak PG, O'Reardon JP, Sampson SM, et al. Transcranial magnetic stimulation in the treatment of major depressive disorder: a comprehensive summary of safety experience from acute exposure, extended exposure, and during reintroduction treatment. J Clin Psychiatry. 2008; 69(2): 222-232. [PubMed: 18232722]

105. Frye RE, Rotenberg A, Ousley M, Pascual-Leone A. Transcranial magnetic stimulation in child neurology: current and future directions. J Child Neurol. 2008; 23(1):79-96. doi: 10.1177/0883073807307972. [PubMed: 18056688]

106. Krishnan C, Santos L, Peterson MD, Ehinger M. Safety of Noninvasive Brain Stimulation in Children and Adolescents. Brain Stimul. 2014; 8(1):76-87. doi:10.1016/j.brs.2014.10.012. [PubMed: 25499471]

107. Gilbert DL, Garvey MA, Bansal AS, Lipps T, Zhang J, Wassermann EM. Should transcranial magnetic stimulation research in children be considered minimal risk? Clin Neurophysiol. 2004; 115(8):1730-1739. doi:10.1016/j.clinph.2003.10.037. [PubMed: 15261851]

108. Quintana H. Transcranial magnetic stimulation in persons younger than the age of 18. J ECT. 2005; 21(2):88-95. http://www.ncbi.nlm.nih.gov/pubmed/15905749. [PubMed: 15905749]

109. Garvey MA, Gilbert DL. Transcranial magnetic stimulation in children. Eur J Paediatr Neurol. 2004; 8(1):7-19. doi:10.1016/j.ejpn.2003.11.002. [PubMed: 15023371] 
110. Bloch Y, Grisaru N, Harel EV, et al. Repetitive transcranial magnetic stimulation in the treatment of depression in adolescents: an open-label study. J ECT. 2008; 24(2):156-159. doi:10.1097/ YCT.0b013e318156aa49. [PubMed: 18580562]

111. Mantovani A, Leckman JF, Grantz H, King RA, Sporn AL, Lisanby SH. Repetitive Transcranial Magnetic Stimulation of the Supplementary Motor Area in the treatment of Tourette Syndrome: report of two cases. Clin Neurophysiol. 2007; 118(10):2314-2315. doi:10.1016/j.clinph. 2007.07.011. [PubMed: 17709291]

112. Sokhadze EM, El-Baz A, Baruth J, Mathai G, Sears L, Casanova MF. Effects of low frequency repetitive transcranial magnetic stimulation (rTMS) on gamma frequency oscillations and eventrelated potentials during processing of illusory figures in autism. J Autism Dev Disord. 2009; 39(4):619-634. doi:10.1007/s10803-008-0662-7. [PubMed: 19030976]

113. Walter G, Tormos JM, Israel JA, Pascual-Leone A. Transcranial magnetic stimulation in young persons: a review of known cases. J Child Adolesc Psychopharmacol. 2001; 11(1):69-75. doi: 10.1089/104454601750143483. [PubMed: 11322748]

114. Chiramberro M, Lindberg N, Isometsä E, Kähkönen S, Appelberg B. Repetitive transcranial magnetic stimulation induced seizures in an adolescent patient with major depression: a case report. Brain Stimul. 2013; 6(5):830-831. doi:10.1016/j.brs.2013.02.003. [PubMed: 23518261]

115. Fregni F, Pascual-Leone A. Technology insight: noninvasive brain stimulation in neurologyperspectives on the therapeutic potential of rTMS and tDCS. Nat Clin Pract Neurol. 2007; 3(7): 383-393. doi:10.1038/ncpneuro0530. [PubMed: 17611487]

116. Miranda PC, Lomarev M, Hallett M. Modeling the current distribution during transcranial direct current stimulation. Clin Neurophysiol. 2006; 117(7):1623-1629. doi:10.1016/j.clinph. 2006.04.009. [PubMed: 16762592]

117. Wagner T, Fregni F, Fecteau S, Grodzinsky A, Zahn M, Pascual-Leone A. Transcranial direct current stimulation: a computer-based human model study. Neuroimage. 2007; 35(3):1113-1124. doi:10.1016/j.neuroimage.2007.01.027. [PubMed: 17337213]

118. Nitsche MA, Nitsche MS, Klein CC, Tergau F, Rothwell JC, Paulus W. Level of action of cathodal DC polarisation induced inhibition of the human motor cortex. Clin Neurophysiol. 2003; 114(4):600-604. http://www.ncbi.nlm.nih.gov/pubmed/12686268. [PubMed: 12686268]

119. Nitsche MA, Cohen LG, Wassermann EM, et al. Transcranial direct current stimulation: State of the art 2008. Brain Stimul. 2008; 1(3):206-223. doi:10.1016/j.brs.2008.06.004. [PubMed: 20633386]

120. Nitsche MA, Paulus W. Excitability changes induced in the human motor cortex by weak transcranial direct current stimulation. J Physiol. 2000; 527(Pt 3):633-639. http:// www.pubmedcentral.nih.gov/articlerender.fcgi?artid=2270099-tool=pmcentrezrendertype $=$ abstract. [PubMed: 10990547]

121. Fregni F, Boggio PS, Valle AC, et al. A sham-controlled trial of a 5-day course of repetitive transcranial magnetic stimulation of the unaffected hemisphere in stroke patients. Stroke. 2006; 37(8):2115-2122. doi:10.1161/01.STR.0000231390.58967.6b. [PubMed: 16809569]

122. Khedr EM, Ahmed MA, Fathy N, Rothwell JC. Therapeutic trial of repetitive transcranial magnetic stimulation after acute ischemic stroke. Neurology. 2005; 65(3):466-468. doi: 10.1212/01.wnl.0000173067.84247.36. [PubMed: 16087918]

123. Boggio PS, Rigonatti SP, Ribeiro RB, et al. A randomized, double-blind clinical trial on the efficacy of cortical direct current stimulation for the treatment of major depression. Int $\mathbf{J}$ Neuropsychopharmacol. 2008; 11(2):249-254. doi:10.1017/S1461145707007833. [PubMed: 17559710]

124. Fregni F, Boggio PS, Nitsche MA, Marcolin MA, Rigonatti SP, Pascual-Leone A. Treatment of major depression with transcranial direct current stimulation. Bipolar Disord. 2006; 8(2):203204. doi:10.1111/j.1399-5618.2006.00291.x. [PubMed: 16542193]

125. Rigonatti SP, Boggio PS, Myczkowski ML, et al. Transcranial direct stimulation and fluoxetine for the treatment of depression. Eur Psychiatry. 2008; 23(1):74-76. doi:10.1016/j.eurpsy. 2007.09.006. [PubMed: 18023968]

126. Valle A, Roizenblatt S, Botte S, et al. Efficacy of anodal transcranial direct current stimulation (tDCS) for the treatment of fibromyalgia: results of a randomized, sham-controlled longitudinal 
clinical trial. J Pain Manag. 2009; 2(3):353-361. http://www.pubmedcentral.nih.gov/ articlerender.fcgi?artid=3002117-tool=pmcentrez-rendertype=abstract. [PubMed: 21170277]

127. Cosmo C, Baptista AF, de Sena EP. Contribution of transcranial direct current stimulation on inhibitory control to assess the neurobiological aspects of attention deficit hyperactivity disorder: randomized controlled trial. JMIR Res Protoc. 2015; 4(2):e56. doi:10.2196/resprot.4138. [PubMed: 25986784]

128. Ditye T, Jacobson L, Walsh V, Lavidor M. Modulating behavioral inhibition by tDCS combined with cognitive training. Exp brain Res. 2012; 219(3):363-368. doi:10.1007/s00221-012-3098-4. [PubMed: 22532165]

129. Fregni F, Boggio PS, Nitsche M, et al. Anodal transcranial direct current stimulation of prefrontal cortex enhances working memory. Exp brain Res. 2005; 166(1):23-30. doi:10.1007/ s00221-005-2334-6. [PubMed: 15999258]

130. Prehn-Kristensen A, Munz M, Göder R, et al. Transcranial Oscillatory Direct Current Stimulation During Sleep Improves Declarative Memory Consolidation in Children With Attention-deficit/ hyperactivity Disorder to a Level Comparable to Healthy Controls. Brain Stimul. 2014; 7(6):793799. doi:10.1016/j.brs.2014.07.036. [PubMed: 25153776]

131. Lenartowicz A, Loo SK. Use of EEG to diagnose ADHD. Curr Psychiatry Rep. 2014; 16(11):498. doi:10.1007/s11920-014-0498-0. [PubMed: 25234074]

132. Paulus W, Peterchev AV, Ridding M. Transcranial electric and magnetic stimulation: technique and paradigms. Handb Clin Neurol. 2013; 116:329-342. doi:10.1016/ B978-0-444-53497-2.00027-9. [PubMed: 24112906]

133. Miniussi C, Ruzzoli M, Walsh V. The mechanism of transcranial magnetic stimulation in cognition. Cortex. 2010; 46(1):128-130. doi:10.1016/j.cortex.2009.03.004. [PubMed: 19356747]

134. Kuo M-F, Nitsche MA. Effects of transcranial electrical stimulation on cognition. Clin EEG Neurosci. 2012; 43(3):192-199. doi:10.1177/1550059412444975. [PubMed: 22956647]

135. Brem A-K, Fried PJ, Horvath JC, Robertson EM, Pascual-Leone A. Is neuroenhancement by noninvasive brain stimulation a net zero-sum proposition? Neuroimage. 2014; 85(Pt 3):10581068. doi:10.1016/j.neuroimage.2013.07.038. [PubMed: 23880500]

136. Luber B. Neuroenhancement by noninvasive brain stimulation is not a net zero-sum proposition. Front Syst Neurosci. 2014; 8:127. doi:10.3389/fnsys.2014.00127. [PubMed: 25071479]

137. Davis NJ. Transcranial stimulation of the developing brain: a plea for extreme caution. Front Hum Neurosci. 2014; 8:600. doi:10.3389/fnhum.2014.00600. [PubMed: 25140146]

138. Maslen H, Earp BD, Cohen Kadosh R, Savulescu J. Brain stimulation for treatment and enhancement in children: an ethical analysis. Front Hum Neurosci. 2014; 8:953. doi:10.3389/ fnhum.2014.00953. [PubMed: 25566011]

139. Gershon AA, Dannon PN, Grunhaus L. Transcranial magnetic stimulation in the treatment of depression. Am J Psychiatry. 2003; 160(5):835-845. [PubMed: 12727683]

140. Janicak PG, Dowd SM, Martis B, et al. Repetitive transcranial magnetic stimulation versus electroconvulsive therapy for major depression: preliminary results of a randomized trial. Biol Psychiatry. 2002; 51(8):659-667. [PubMed: 11955466]

141. Moll GH, Heinrich H, Trott G, Wirth S, Rothenberger A. Deficient intracortical inhibition in drug-naive children with attention-deficit hyperactivity disorder is enhanced by methylphenidate. Neurosci Lett. 2000; 284(1-2):121-125. http://www.ncbi.nlm.nih.gov/pubmed/10771177. [PubMed: 10771177]

142. Moll GH, Heinrich H, Trott GE, Wirth S, Bock N, Rothenberger A. Children with comorbid attention-deficit-hyperactivity disorder and tic disorder: evidence for additive inhibitory deficits within the motor system. Ann Neurol. 2001; 49(3):393-396. http://www.ncbi.nlm.nih.gov/ pubmed/11261515. [PubMed: 11261515]

143. Uclés P, Serrano JL, Rosa F. Central conduction time of magnetic brain stimulation in attentiondeficit hyperactivity disorder. J Child Neurol. 2000; 15(11):723-728. http:// www.ncbi.nlm.nih.gov/pubmed/11108505. [PubMed: 11108505]

144. Richter MM, Ehlis A-C, Jacob CP, Fallgatter AJ. Cortical excitability in adult patients with attention-deficit/hyperactivity disorder (ADHD). Neurosci Lett. 2007; 419(2):137-141. doi: 10.1016/j.neulet.2007.04.024. [PubMed: 17481816] 
145. Gilbert DL, Zhang J, Lipps TD, et al. Atomoxetine treatment of ADHD in Tourette syndrome: reduction in motor cortex inhibition correlates with clinical improvement. Clin Neurophysiol. 2007; 118(8):1835-1841. doi:10.1016/j.clinph.2007.05.065. [PubMed: 17588810]

146. Orth M, Rothwell JC. Motor cortex excitability and comorbidity in Gilles de la Tourette syndrome. J Neurol Neurosurg Psychiatry. 2009; 80(1):29-34. doi:10.1136/jnnp.2008.149484. [PubMed: 18931001]

147. Moll GH, Heinrich H, Rothenberger A. Methylphenidate and intracortical excitability: opposite effects in healthy subjects and attention-deficit hyperactivity disorder. Acta Psychiatr Scand. 2003; 107(1):69-72. http://www.ncbi.nlm.nih.gov/pubmed/12558545. [PubMed: 12558545]

148. Kirschner J, Moll GH, Fietzek UM, et al. Methylphenidate enhances both intracortical inhibition and facilitation in healthy adults. Pharmacopsychiatry. 36(2):79-82. doi:10.1055/s-2003-39049. [PubMed: 12734766]

149. Ilić TV, Korchounov A, Ziemann U. Methylphenidate facilitates and disinhibits the motor cortex in intact humans. Neuroreport. 2003; 14(5):773-776. doi:10.1097/01.wnr.0000063251.41814.70. [PubMed: 12692481]

150. Gilbert DL, Ridel KR, Sallee FR, Zhang J, Lipps TD, Wassermann EM. Comparison of the inhibitory and excitatory effects of ADHD medications methylphenidate and atomoxetine on motor cortex. Neuropsychopharmacology. 2006; 31(2):442-449. doi:10.1038/sj.npp.1300806. [PubMed: 16034446] 


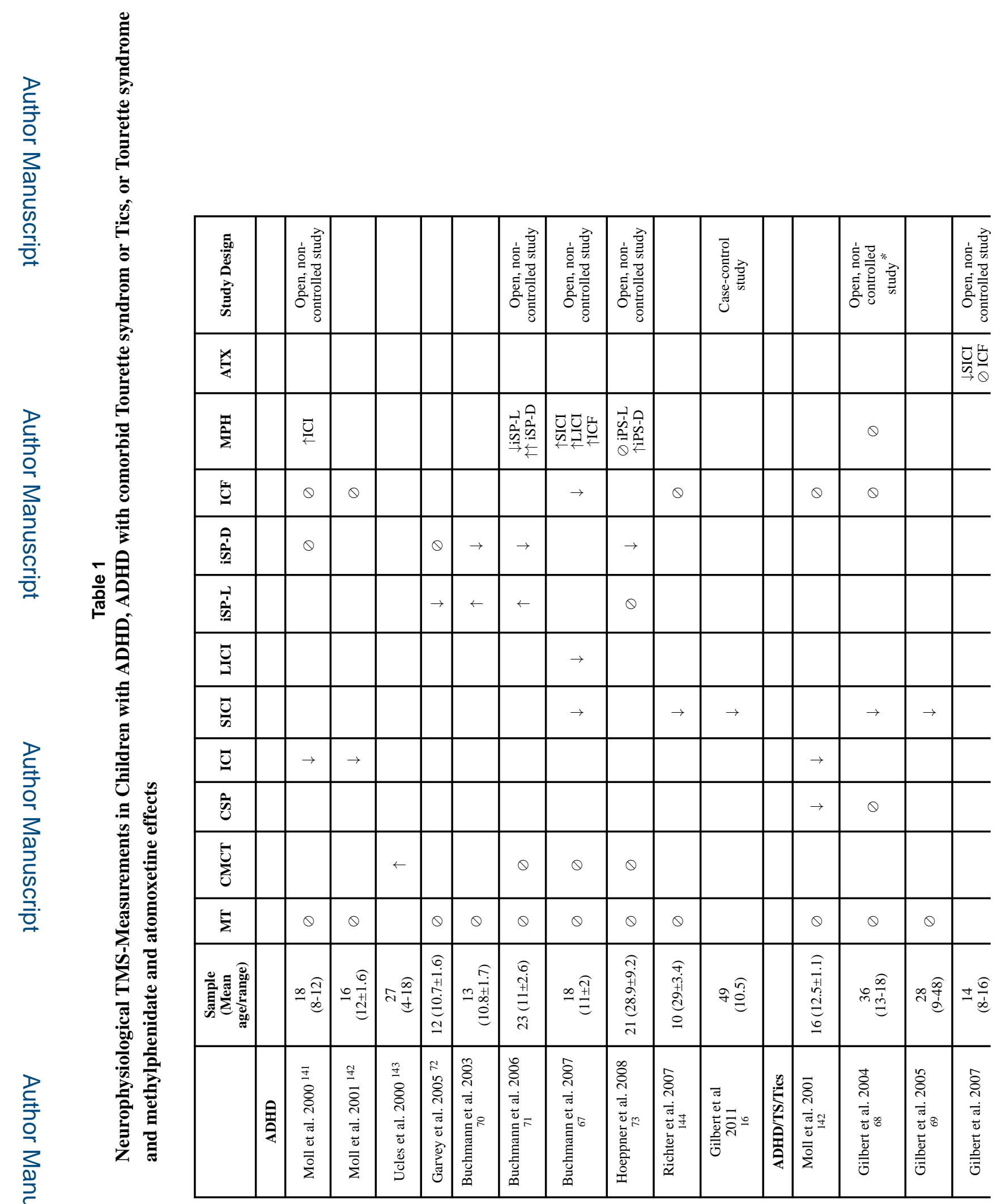

J Child Neurol. Author manuscript; available in PMC 2017 May 01. 


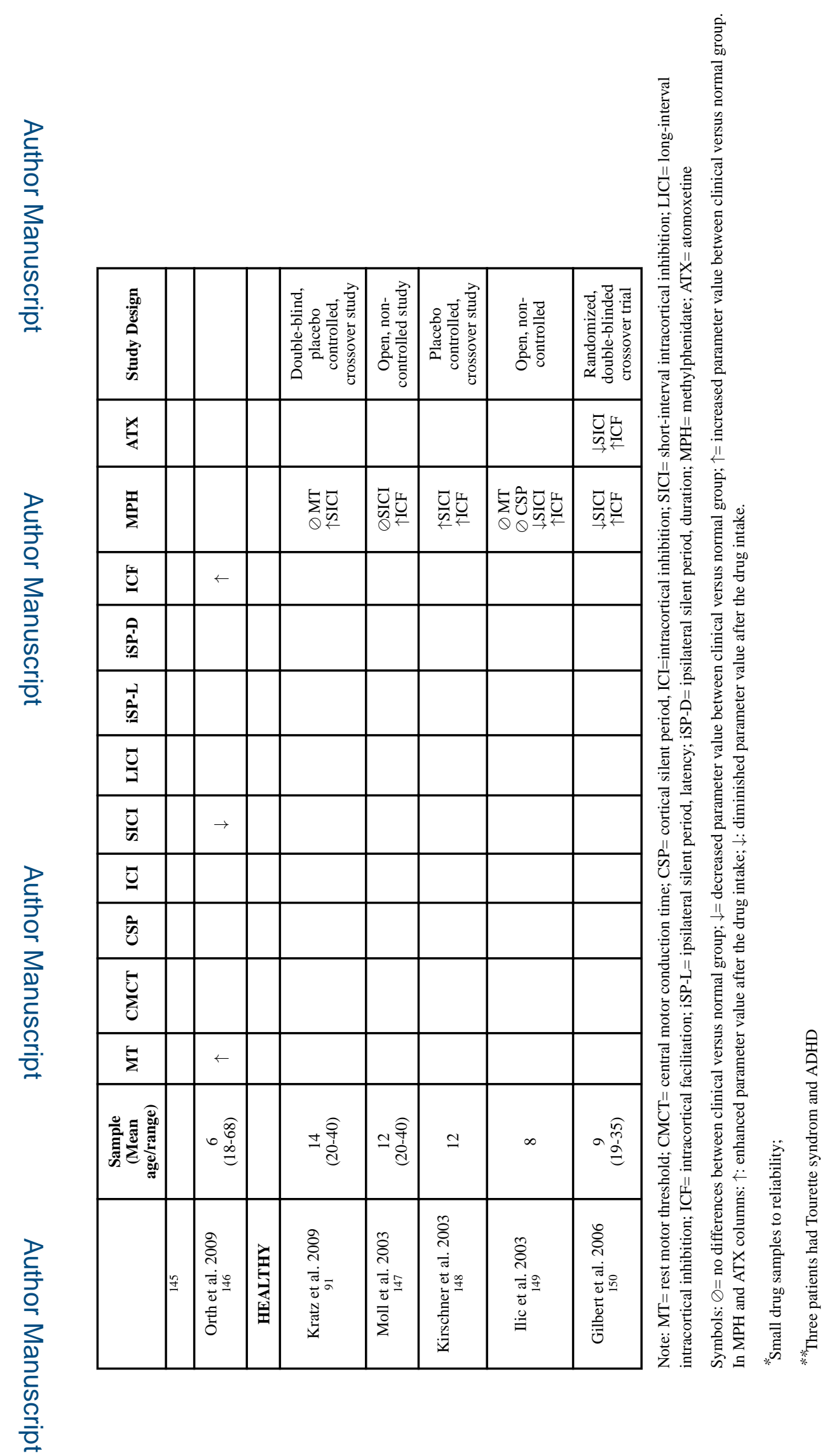

J Child Neurol. Author manuscript; available in PMC 2017 May 01. 